\title{
Functional Shape Variation in the Cercopithecine Masticatory Complex Michelle Singleton
}

\section{INTRODUCTION}

The study of cranial shape variation is central to physical anthropology, and the prevalence of cranial allometry in cercopithecine monkeys (Cercopithecidae Gray, 1821) has made them favorite subjects for investigating links between cranial development, function, and form (Antón, 1996; Bouvier, 1986a; Hylander, 1979, 1985; Leigh et al., 2003; Lucas, 1981, 1982; Ravosa, 1990; Ravosa and Profant, 2000; Ravosa and Shea, 1994; Shea, 1992; Vinyard and Ravosa, 1998). By distinguishing shape differences due primarily to body size from those with specific functional or phylogenetic significance (Gould, 1975; Shea, 1983a, 1985), such studies both elucidate modern primate adaptations and improve interpretations of cranial shape variation in the primate fossil record. The cercopithecine tribe Papionini (Table 1) - a monophyletic taxon comprising macaques (genus Macaca), mangabeys (Cercocebus and Lophocebus), mandrills and drills (Mandrillus), and baboons (Papio and Theropithecus) (Delson, 1975a, b; Hill, 1974; Kuhn, 1967; Strasser and

Michelle Singleton - Department of Anatomy, Midwestern University, Downers Grove, IL 60515. Modern Morphometrics in Physical Anthropology, edited by Dennis E. Slice. Kluwer Academic/Plenum Publishers, New York, 2005. 
Table 1. Taxonomy of species sampled

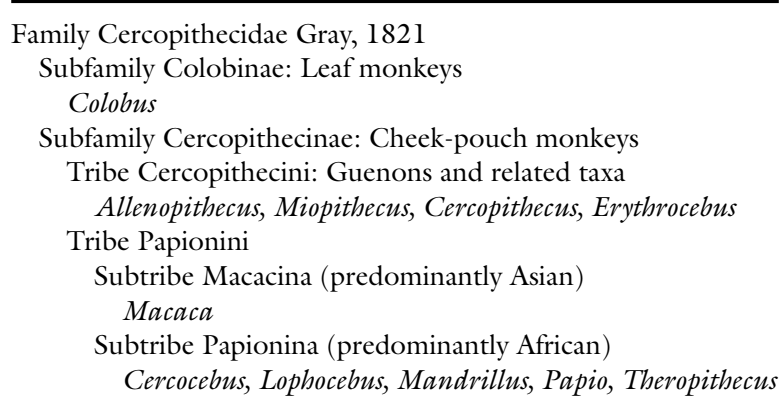

Note: Cercopithecid cladistic relationships are shown in Figure 1. Source: Cercopithecid taxonomy after Szalay and Delson (1979).

Delson, 1987; Szalay and Delson, 1979)—has received particular attention from researchers interested in allometry as a source of cranial homoplasy (Collard and Wood, 2000; Fleagle and McGraw, 2001; Leigh et al., 2003; Lockwood and Fleagle, 1999). The mangabeys, small- to medium-sized monkeys with moderately prognathic faces, were historically considered sister taxa (Figure la) to the exclusion of Papio and Mandrillus, large-bodied taxa with long faces and enlarged canines (Hill, 1974; Kuhn, 1967; Strasser and Delson, 1987; Szalay and Delson, 1979; Thorington and Groves, 1970). But molecular phylogenetic analyses (Figure $\mathrm{lb}$ ) have consistently rejected mangabey monophyly, instead linking Cercocebus and Lophocebus with Mandrillus and Papio, respectively (Barnicot and Hewett-Emmett, 1972; Cronin and Sarich, 1976; Disotell, 1994; Disotell et al., 1992; Dutrillaux et al., 1979, 1982; Harris, 2000; Harris and Disotell, 1998; Hewett-Emmett et al., 1976; Page et al., 1999; Van Der Kuyl et al., 1995). Given the marked size differences between the newly recognized papionin sister taxa (Delson et al., 2000), simple ontogenetic scaling - shape difference arising from truncation or extension of shared ancestral ontogenetic trajectories (Gould, 1966; Shea, 1983b, 1985)—was considered the most likely cause of papionin facial homoplasy (Harris, 2000; Lockwood and Fleagle, 1999; Ravosa and Profant, 2000; Shah and Leigh, 1995). But comparative studies have revealed a complex interplay of interspecific size allometry (Singleton, 2002), shared ontogenetic scaling patterns (Collard and O'Higgins, 2001), and allometric dissociations (Leigh et al., 2003; Shah and Leigh, 1995) contributing to the pervasive, nonhomologous similarities between like-sized members of the disparate papionin clades. 
(a)

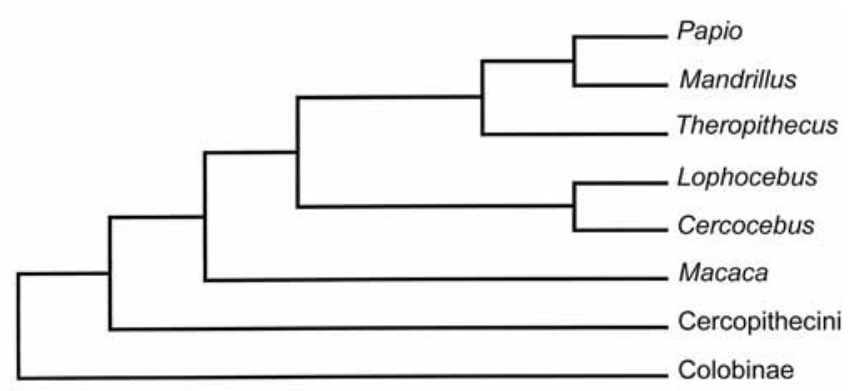

(b)

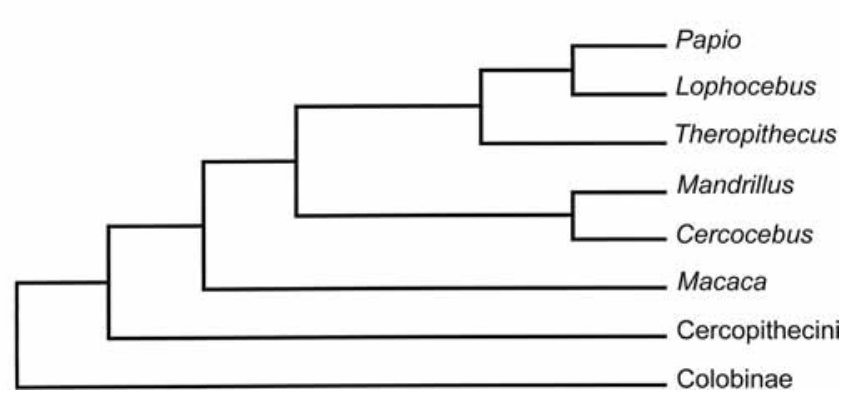

Figure 1. Cladograms of the Cercopithecidae showing alternative hypotheses of papionin relationships. Traditional phylogenies (a) identified mangabeys-Cercocebus and Lophocebus - as sister taxa (Delson and Dean, 1993; Strasser and Delson, 1987; among others); molecular phylogenies (b) reject mangabey monophyly (Disotell, 1994; Harris, 2000; Harris and Disotell, 1998).

While these studies have increased our understanding of papionin facial allometries and clarified the ontogenetic basis of the resultant cranial shape similarities, the polarity and adaptive significance of these trends are still contested (Harris, 2002; Ravosa and Profant, 2000). The majority of workers favor the view that long faces are derived in papionins (Benefit and McCrossin, 1991, 1993; Collard and O'Higgins, 2002; Cronin and Sarich, 1976; Delson, 1975a, b; Disotell, 1994, 1996; Harris, 2000, 2002; Jolly, 1970; Strasser and Delson, 1987), but others maintain that facial prognathism is the basal African papionin condition (Groves, 1978; Kingdon, 1997). Whereas ontogenetic studies incorporating a broader range of cercopithecine taxa should help to establish the polarity of papionin facial growth patterns, consideration of the biomechanical consequences of differing facial allometries is needed to ascertain their broader evolutionary significance. Deviations from ancestral ontogenetic patterns, such as observed in papionins (Collard and O'Higgins, 2001; Leigh et al., 2003; Shah and Leigh, 1995), frequently 
indicate selection for altered size-shape relationships that have functional and adaptive implications beyond simple size change (Gould, 1975; Shea, 1983b, 1985). Specifically, transposition of allometric trajectories often reflects the maintenance of geometric similarity or biomechanical equivalence as species evolve into new size ranges (Gould, 1971; Ravosa, 1992; Shea, 1983b, 1995; Smith, 1993; Vinyard and Ravosa, 1998). Conversely, selection for new or enhanced functional capacities may cause dissociation of scaling trajectories between closely related taxa (Ravosa, 1990; Shea, 1985) or convergence of ontogenetic allometries and homoplastic similarity in distantly related forms (Demes et al., 1986; Ravosa, 1992).

The mechanical constraints of mastication are a fundamental determinant of maxillofacial form (Sakka, 1985), and diet is a major influence upon cercopithecine facial scaling (Antón, 1996; Hylander, 1977, 1979; Ravosa, 1990; Shea, 1983b; Vinyard and Ravosa, 1998). Conveniently, the African papionin clade (subtribe Papionina) encompasses two distinct ecomorphs: small-bodied and relatively arboreal mangabeys, which are heavily reliant on hard fruits, nuts, and seeds; and large-bodied, terrestrial forms (Papio, Mandrillus) characterized by extreme facial prognathism, greatly enlarged canines, and diets incorporating a variety of resistant foods. Thus, it is highly plausible that documented allometric shifts among papionins (Collard and O'Higgins, 2001; Leigh et al., 2003; Shah and Leigh, 1995) result from selection for specific functional capacities, that is, functional convergence. Confirmation that facial allometries in Papio and Mandrillus (or Cercocebus and Lophocebus) produce novel size-shape associations (i.e., forms) with similar biomechanical properties would support a hypothesis of functional convergence, clarify extant papionin adaptations, and potentially shed light on the selective pressures to which ancestral papionins were subject.

Scaling of the primate facial complex has traditionally been studied using linear regression of interlandmark distances analyzed within the framework of the bivariate allometric model (Gould, 1966; Huxley, 1932). The multivariate generalization of allometry (Jolicoeur, 1963) and Euclidean distance matrix analysis (EDMA)(Richtsmeier and Lele, 1993) have also been used to investigate size-related patterns of shape variation. More recent studies (Collard and O’Higgins, 2001; O'Higgins and Jones, 1998; Penin et al., 2002; Singleton, 2002; Vidarsdottir et al., 2002) have combined classic allometric models with landmark-based geometric morphometric analysis (Bookstein, 1996; Dryden and Mardia, 1998) to investigate interspecific and ontogenetic allometries in a 
range of anthropoid primates. This geometric approach has yet to be applied to comparative analysis of functional allometries. Yet, it would seem to be ideally suited to investigations of functional scaling. Whereas traditional size allometry deals with scaling of individual variables relative to size and biomechanical allometry is narrowly concerned with scaling relationships among variables relative to a priori biomechanical models (Smith, 1993), neither approach adequately describes how the functional geometry of a configuration changes with changing size. By contrast, allometric analysis of geometrically derived shape variables quantifies differences in relative distance and relative position among multiple landmarks relative to size (Rohlf and Marcus, 1993), potentially bridging the gap between these previously incommensurate allometric categories.

The cercopithecine masticatory apparatus is an ideal test case for this proposition. Certain aspects of jaw function may be modeled as simple lever systems (Greaves, 1974; Hylander, 1979; Ravosa, 1990; Spencer, 1999), and primate masticatory muscle forces are known to scale isometrically with cranial size (Cachel, 1984; Hylander, 1985). Thus, geometric shape differences affecting the relative positions of joints, muscle attachments, and bite points have predictable biomechanical consequences (Hylander, 1985; Ravosa, 1990), easily interpretable in terms of relative functional capacities. Prior studies of facial biomechanics (Antón, 1996; Bouvier, 1986a; Greaves, 1974, 1995; Hylander, 1979; Lucas, 1981, 1982; Ravosa, 1990; Smith, 1984; Vinyard and Ravosa, 1998) furnish models for the functional interpretation of shape variation and permit validation of results. Therefore, this study employs a combination of geometric morphometric and statistical analytic methods to examine patterns of shape variation in the cercopithecine masticatory complex. Its goals are to evaluate the efficacy of geometric morphometrics for functional allometric analysis; to document the phylogenetic distribution of adult masticatory scaling patterns within Cercopithecinae; to interpret the functional consequences of differing adult facial allometries in light of established biomechanical models; and to explore the potential adaptive significance of papionin facial homoplasy.

\section{MATERIALS AND METHODS}

The study sample comprised 450 adult individuals representing all commonly recognized cercopithecine genera and two colobine outgroups (see Table 2). 
Table 2. Within-species correlations

\begin{tabular}{|c|c|c|c|c|c|c|}
\hline \multirow[t]{2}{*}{ Taxon } & \multicolumn{2}{|c|}{$n$} & \multicolumn{2}{|c|}{ PCl } & \multicolumn{2}{|c|}{ PC2 } \\
\hline & Female & Male & SIZE & MLVR & SIZE & FL \\
\hline Colobus angolensis cottoni & 12 & 22 & 0.69 & 0.57 & $0.56^{b}$ & $0.60^{b}$ \\
\hline Colobus guereza kikuyuensis & 10 & 20 & 0.66 & $0.50^{b}$ & $0.44^{a}$ & $0.47^{a}$ \\
\hline Cercopithecus ascanius ngamiensis & 19 & 8 & 0.76 & 0.63 & 0.81 & 0.81 \\
\hline Cercopithecus mona & 23 & 20 & 0.63 & 0.53 & 0.65 & 0.67 \\
\hline Allenopithecus nigroviridis & 3 & 3 & $0.89^{a}$ & $0.94^{a}$ & $0.94^{b}$ & $0.91^{a}$ \\
\hline Erythrocebus patas & 4 & 9 & 0.89 & 0.80 & 0.84 & 0.88 \\
\hline Miopithecus ougouensis & 15 & 6 & $0.53^{a}$ & $0.34^{\mathrm{NS}}$ & 0.67 & $0.56^{a}$ \\
\hline Cercocebus galeritus agilis & 9 & 7 & 0.77 & 0.58 & 0.86 & 0.89 \\
\hline Cercocebus torquatus torquatus & 11 & 18 & 0.75 & 0.65 & 0.73 & 0.73 \\
\hline Lophocebus albigena jobnstoni & 15 & 24 & 0.82 & 0.62 & 0.62 & 0.61 \\
\hline Macaca fascicularis & 17 & 26 & 0.87 & 0.67 & 0.67 & 0.64 \\
\hline Mandrillus leucophaeus & 8 & 19 & 0.88 & 0.76 & 0.85 & 0.86 \\
\hline Mandrillus sphinx & 8 & 13 & 0.87 & 0.81 & 0.80 & 0.81 \\
\hline Papio hamadryas anubis & 21 & 42 & 0.90 & 0.82 & 0.71 & 0.74 \\
\hline Theropithecus gelada & 13 & 25 & 0.78 & 0.63 & 0.68 & 0.68 \\
\hline
\end{tabular}

Notes: Within-species Pearson product moment correlations for principal shape components with log centroid size (SIZE), log masseter lever arm length (MLVR), and log facial length (FL). All correlations are significant at $p<0.001$ except as indicated.

NS, not significant.

${ }^{a} p<0.05$.

${ }^{b} p<0.01$.

Following published protocols (Frost et al., 2003; Singleton, 2002), 45 threedimensional craniofacial landmarks were recorded; missing data points were estimated by reflection (Singleton, 2002). Linear interlandmark distances (see below) were computed from raw coordinates and log-transformed. Specimens were scaled to unit centroid size and aligned via generalized Procrustes analysis (GPA) using tpsSmall vs 1.19 (Rohlf, 1998). Where shape variation about the Procrustes mean is sufficiently small, Procrustes-aligned coordinates may be used in lieu of Kendall tangent-space coordinates as the basis of parametric statistical analysis (Dryden and Mardia, 1998; Rohlf, 1999; Slice, 2001). The least squares regression of Procrustes distances against Euclidean (tangentspace) distances (slope $=0.9962, r=0.9999)$ computed by tpsSmall vs 1.19 (Rohlf, 1998) supports this assumption, and Procrustes-aligned coordinates were accepted as a reasonable approximation of the orthogonal tangent space projection.

A subset of five landmarks-Postglenion (PGL), Zygomaxillare Inferior (ZMI), Distal M3 (DM3), Ml-M2 Contact (M12), and Prosthion (PRO) (Figure 2; see Frost et al., 2003 for landmark definitions)—was selected to 

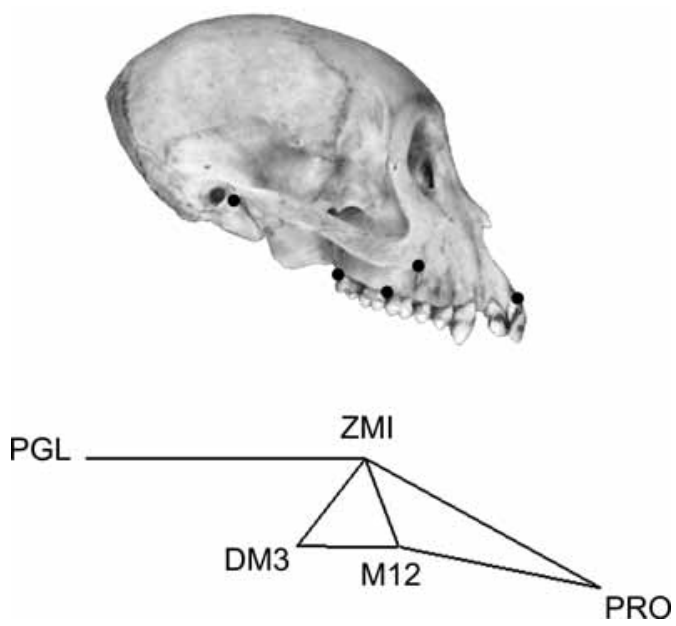

Figure 2. Top: Lateral view of representative cercopithecine skull (female Lophocebus albigena) showing masticatory landmarks employed in this study. Bottom: Wireframe representation of the sample Procrustes mean configuration for the five masticatory landmarks (right side only). PGL = Postglenion, $\mathrm{ZMI}=$ Zygomaxillare Inferior, $\mathrm{DM} 3=$ Distal M3 at alveolar margin, $\mathrm{M12}=\mathrm{M1}-\mathrm{M} 2$ contact at alveolar margin, $\mathrm{PRO}=$ Prosthion

capture specific functional aspects of the masticatory system including: (a) the relative positions of the temporomandibular joint (TMJ) and zygomatic root; (b) the length and relative position of the palate; and (c) the positions of maxillary bite points. These landmarks were chosen to correspond to endpoints of linear measures employed in prior studies of the primate masticatory system (e.g., Ravosa, 1990). By so doing, it was hoped to validate the results of geometric analysis against documented patterns of masticatory scaling and to evaluate the utility of geometric analysis for elucidating patterns of functional variation.

To compensate for the lack of statistical independence among landmarks due to morphological integration and the constraints of translation, rotation, and scaling imposed by GPA (Dryden and Mardia, 1998; Rohlf, 1999), principal components analysis (PCA) was conducted on the covariance matrix of Procrustes-aligned coordinates for the masticatory landmarks. This procedure ordinates specimens relative to mutually orthogonal axes of shape variation and yields a small number of uncorrelated summary shape variables, namely the principal component (PC) scores (Dryden and Mardia, 1998). The signs (positive or negative) of these scores are arbitrary and analysis-specific; thus, it is their 
relative (rather than absolute) values that signify differences in shape among specimens. It should also be emphasized that, because GPA eliminates only the effects of scale (i.e., absolute size), principal shape components incorporate both size-correlated (allometric) and size-independent (residual) variation. Patterns of shape variation summarized by selected shape components were explored using the Morphologika morphometrics package (O'Higgins and Jones, 1999) to generate wireframe representations of variation along corresponding shape axes. Bivariate scatterplots of shape component (PC) scores against independent size variables were used to identify potential allometric relationships, the strengths of which were assessed by correlation analyses within species and tribes.

The choice of independent variables for cranial allometry has been a subject of some debate (Bouvier, 1986a, b; Hylander, 1985; Ravosa, 1990; Smith, 1993). Ontogenetic and functional allometries are most commonly examined relative to measures of cranial or facial length; for biomechanical allometry, the choice of independent variable is determined by the mechanical relationships under consideration (Bouvier, 1986a, b; Hylander, 1985; Ravosa, 1990; Smith, 1993). For Procrustes-based analyses, the appropriate size metric is centroid size, a Mosimann variable (Mosimann and Malley, 1979) approximately uncorrelated with all shape variables assuming isotropic landmark error (Bookstein, 1996; Slice et al., 1996); thus, log centroid size was adopted as the sole estimate of cranial size. As previously noted, scaling relationships for the principal shape components are expected to subsume both biomechanical allometry-scaling relationships among landmarks (Smith, 1993)—and size allometry—scaling relationships for individual landmarks. To test this supposition, scaling of shape components against biomechanically appropriate variables - masseter lever arm length (MLVR, distance from PGL to ZMI) and facial length (FL, distance from PGL to PRO)—was examined to confirm certain functional interpretations.

Between-species differences in adult intraspecific scaling were tested by least squares regression and analysis of covariance (ANCOVA). Species-bycovariate interaction effects were tested to rule out heterogeneity of slopes, and a posteriori comparisons of estimated marginal means-species means adjusted for covariate effects-were performed to identify significant differences in regression elevations. This approach was adopted in preference to interspecific regression of species means because it both permits pairwise significance testing of between-species scaling differences and, more importantly, avoids a priori functional or taxonomic grouping of species. 


\section{RESULTS}

\section{Functional Shape Variation}

The first 8 of 15 PCs accounted for $95 \%$ of total shape variance. Although specimens are scaled to unit centroid size, the lst Principal Component (66\% of total shape variance) appears to ordinate individuals on the basis of size, separating small- from large-bodied species and females from conspecific males (Figure 3). Visualization of shape variation along the lst Principal Component axis (Figure 3 ) indicates that animals with more negative scores possess relatively short palates, which are retracted relative to ZMI, such that molar bite points lie posterior to the zygomatic. ZMI, which marks the anteriormost extent of the masseter origin, lies well anterior to the TMJ. In biomechanical terms, more negative scores correspond to relatively long masseter lever arms and relatively short dental load arms. This favorable input- to output-ratio results in increased mechanical advantage (MA) for the masseter and increased molar and incisal bite force magnitudes relative to cranial size (Hylander, 1985; Ravosa, 1990). By contrast, animals with more positive scores are characterized by more posteriorly positioned zygomatics, anteriorly positioned bite points with the M12 point anterior to ZMI, and relatively long palates. This configuration results in less favorable input- to output-ratios, reduced masseter MA, and decreased relative bite forces, particularly in the incisal region (Hylander, 1985; Ravosa, 1990; Spencer, 1999).

The 2nd Principal Component (10\% of total shape variance) summarizes variation in the height of the TMJ independent of facial length (Figure 3). Negative scores signify decreased vertical separation between the TMJ and alveolar margin relative to facial length; positive scores, increased relative TMJ height. Miopithecus and papionin species fall toward the negative end of the axis; Colobus, Theropithecus, and the remaining cercopithecins at its positive end. Females exhibit more negative scores than conspecific males. Variation in TMJ height relative to facial length is an important determinant of jaw gape, that is, maximum mandibular opening (Greaves, 1974; Herring and Herring, 1974; Lucas, 1981, 1982). With all other factors held constant, decreased relative TMJ height results in increased vertical mandibular displacement and greater gape (Greaves, 1974; Lucas, 1982; Ravosa, 1990; Smith, 1984). It may also increase the vertical component of bite force, especially in the incisor region (Ravosa, 1990). Thus, relatively negative scores on the 2 nd Principal shape component signify enhanced gape and potentially more forceful incisal 


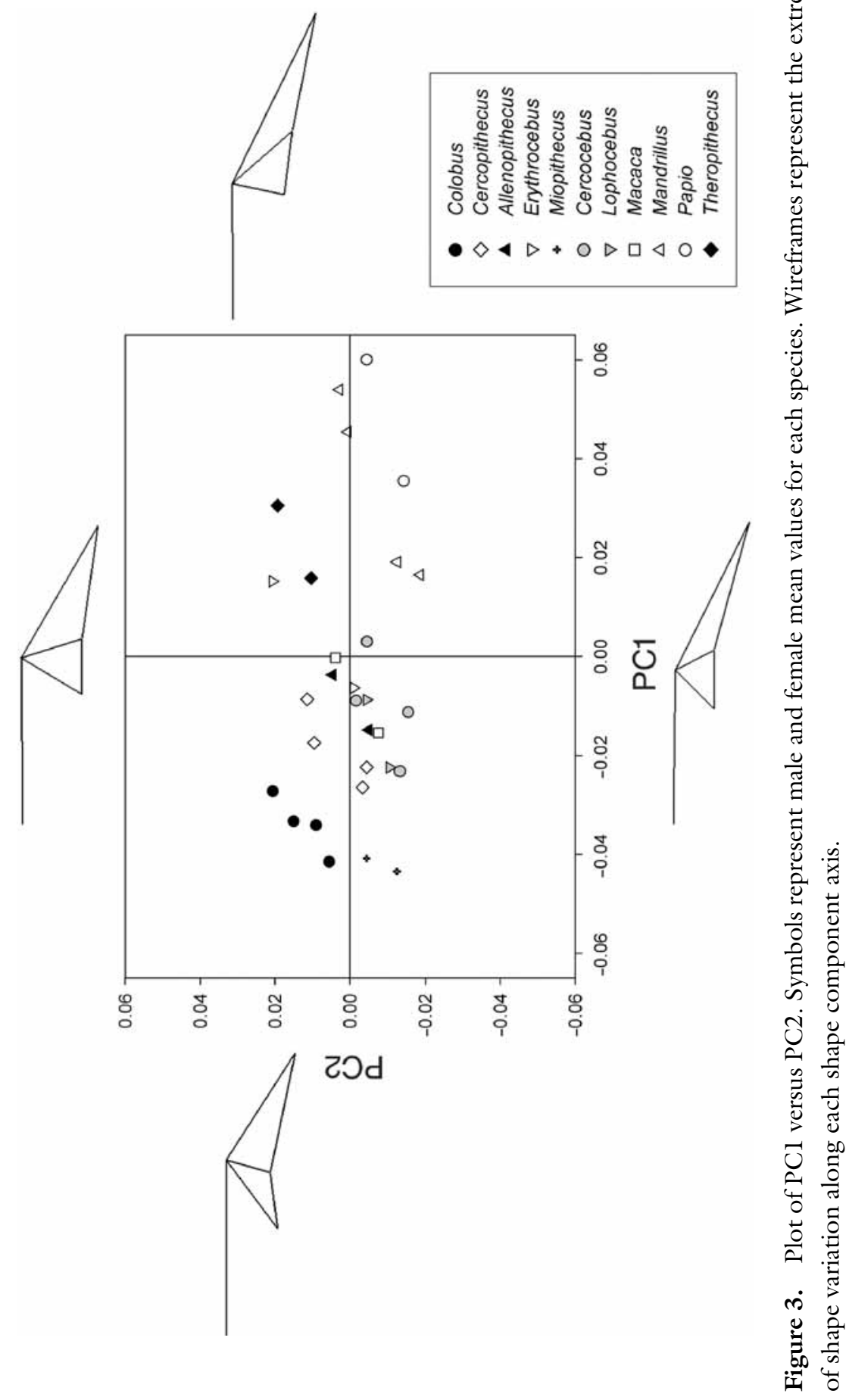


biting, whereas positive scores indicate decreased relative gape and reduced vertical bite force components.

\section{Functional Allometry-Principal Component 1}

The lst Principal Component is strongly linearly correlated with log centroid size (Figure 4a) within the majority of cercopithecine species sampled (Table 2) and within the two cercopithecine tribes (Table 3 ). The ANCOVA of PCl by species with $\log$ centroid size as the covariate is highly significant $(F=371.91$, $\left.p<0.001, r^{2}=0.96\right)$. Homogeneity of slopes is confirmed, but ANOVA of estimated marginal means (linearly independent contrasts) finds significant differences $(F=21.8, p<0.001)$ among regression elevations. Colobus, mangabeys, and Cercopithecus mona have negative adjusted mean values, in contrast with all remaining cercopithecins and papionins, which have positive means (Table 4). There are relatively few significant pairwise differences in elevations among species either within or between groups (Table 5). However, the two colobine species are significantly different from all cercopithecines except Miopithecus and C. galeritus. Among papionins, mangabey species are significantly different from Macaca, Mandrillus leucophaeus, and Papio but not M. sphinx or Theropithecus.

Scaling of PCl against MLVR (not shown) resembles that for centroid size, although full-sample, within-species, and within-tribe correlations are generally weaker (Tables 2,3 ). The ANCOVA of PCl by species with MLVR as the covariate is highly significant statistically $\left(F=233.1, p<0.001, r^{2}=0.94\right)$, homogeneity of slopes is confirmed, and the test of independent contrasts is again significant $(F=70.2, p<0.001)$. Adjusted mean values (Table 4$)$ separate colobines from cercopithecines and mangabeys from all other papionins, Erythrocebus and Allenopithecus. However, adjusted means for Miopithecus and the two Cercopithecus species are more similar to mangabeys, and taxonomic patterning of between-species comparisons is less clear than for centroid size (Table 5).

Scaling of the lst Principal Component, summarizing shape variation tied to MA of the masseter muscle, is consistent with known patterns of cercopithecine facial allometry (Bookstein, 1985; Cheverud and Richtsmeier, 1986; Cochard, 1985; Collard and O'Higgins, 2001; Freedman, 1962, 1963; Leigh et al., 2003; McNamara et al., 1976; Profant and Shea, 1994; Ravosa and Profant, 2000; Ravosa and Shea, 1994; Singleton, 2002; Swindler and Sirianni, 1973; 

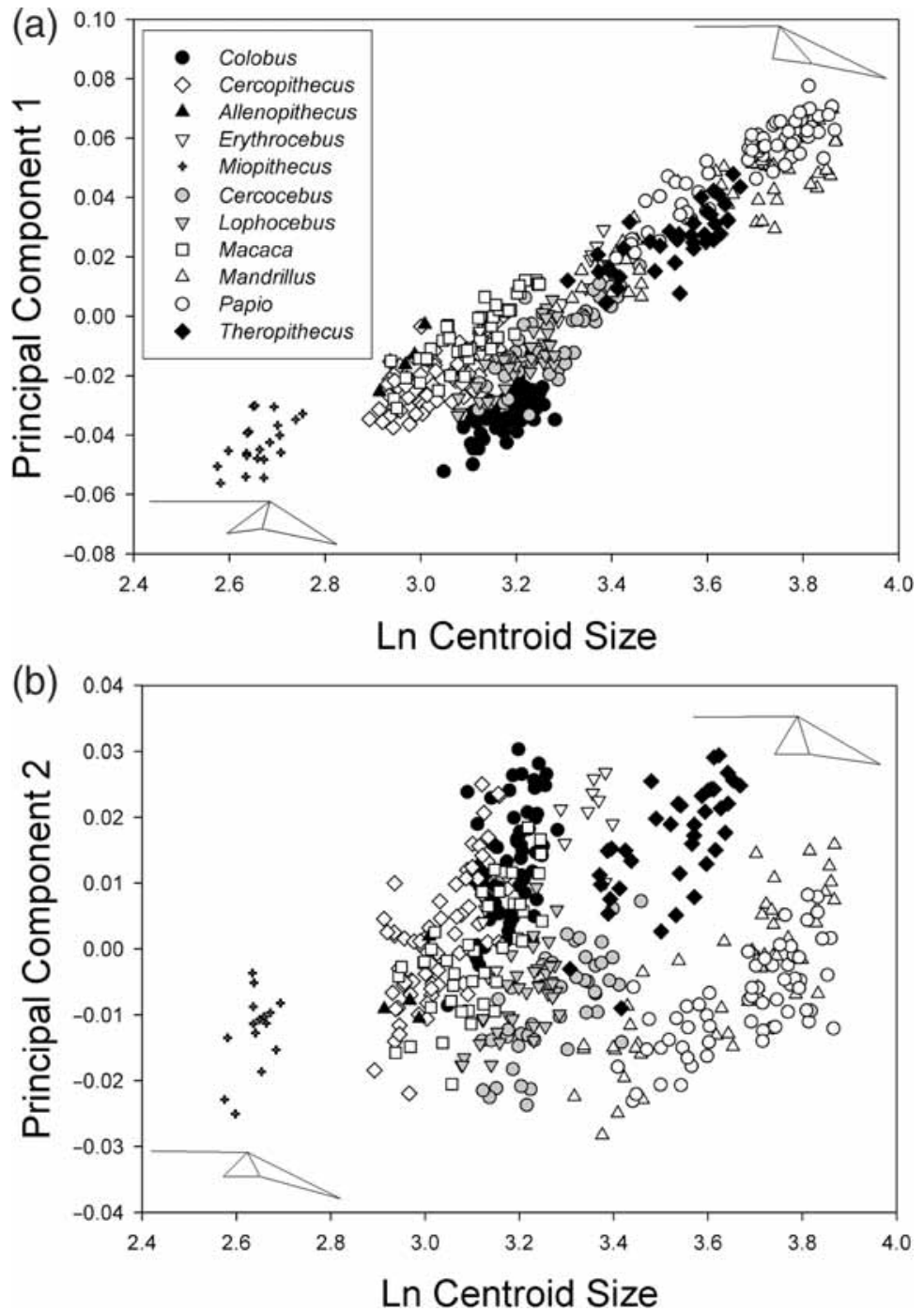

Figure 4. Plots of principal shape components against log centroid size. Wireframes represent extremes of shape variation for each component. (a) Intraspecific scaling of PCl relative to size is largely uniform among cercopithecines, but negative displacement of allometric lines in mangabeys reflects facial retraction resulting in increased mechanical advantage and enhanced relative bite forces. (b) Scaling of PC2 differs between cercopithecine tribes. Negative displacement of papioninan allometric lines implies decreased relative temporomandibular joint height and increased relative jaw gape; further dissociations results in geometric similarity of gape among African papionins. 
Table 3. Within-tribe correlations by sex

\begin{tabular}{llllll}
\hline & \multicolumn{2}{c}{ PCl } & & \multicolumn{2}{c}{ PC2 } \\
\cline { 6 - 6 } \cline { 5 - 6 } \cline { 5 - 6 } & SIZE & MLVR & & SIZE & FL \\
\hline $\begin{array}{llllll}\text { Cercopithecin } \\
\text { Female }\end{array}$ & $0.94^{a}$ & $0.86^{\mathrm{NS}}$ & & $0.98^{b}$ & $0.98^{b}$ \\
$\begin{array}{c}\text { Male } \\
\text { Papionin }\end{array}$ & $0.97^{b}$ & $0.94^{a}$ & & $0.96^{a}$ & $0.95^{a}$ \\
Female & $0.93^{b}$ & $0.78^{a}$ & & $0.04^{\mathrm{NS}}$ & $0.04^{\mathrm{NS}}$ \\
Male & $0.97^{b}$ & $0.90^{b}$ & & $0.17^{\mathrm{NS}}$ & $0.12^{\mathrm{NS}}$ \\
\hline
\end{tabular}

Notes: Within-tribe Pearson product moment correlations for species mean principal component scores by sex. Abbreviations as in Table 2.

NS not significant.

${ }^{a} p<0.05$.

${ }^{b} p<0.01$.

Table 4. Estimated marginal means

\begin{tabular}{|c|c|c|c|c|}
\hline \multirow[t]{2}{*}{ Taxon } & \multicolumn{2}{|c|}{$\mathrm{PCl}$} & \multicolumn{2}{|c|}{ PC2 } \\
\hline & SIZE & MLVR & SIZE & FL \\
\hline C. angolensis & -0.027 & -0.039 & 0.016 & 0.016 \\
\hline C. guereza & -0.022 & -0.030 & 0.024 & 0.024 \\
\hline C. ascanius & 0.005 & -0.004 & 0.028 & 0.026 \\
\hline C. mona & -0.004 & -0.012 & 0.023 & 0.021 \\
\hline A. nigroviridis & 0.012 & 0.005 & 0.022 & 0.021 \\
\hline E. patas & 0.009 & 0.009 & 0.014 & 0.014 \\
\hline M. ougouensis & 0.015 & -0.012 & 0.051 & 0.033 \\
\hline M. fascicularis & 0.015 & 0.010 & 0.012 & 0.010 \\
\hline C. torquatus & -0.004 & -0.008 & -0.010 & -0.004 \\
\hline C. galeritus & -0.011 & -0.016 & -0.003 & -0.003 \\
\hline L. albigena & -0.004 & -0.011 & -0.002 & -0.012 \\
\hline M. leucophaeus & 0.011 & 0.016 & -0.024 & -0.024 \\
\hline M. sphinx & 0.002 & 0.014 & -0.022 & -0.023 \\
\hline P. hamadryas & 0.013 & 0.027 & -0.024 & -0.024 \\
\hline T. gelada & 0.005 & 0.013 & 0.002 & 0.002 \\
\hline
\end{tabular}

Note: Species mean values adjusted for the effects of the covariate.

Swindler et al., 1973). With size increase, relative palate length increases; relative masseter lever length decreases; and molar bite points shift forward relative to the zygomatic root, all leading to reduced relative MA and decreased relative bite forces at larger cranial sizes (Hylander, 1979; Ravosa, 1990). The significant negative displacement of the Colobus regression reflects a shortening and retraction of the palate, conferring increased MA and greater bite forces 


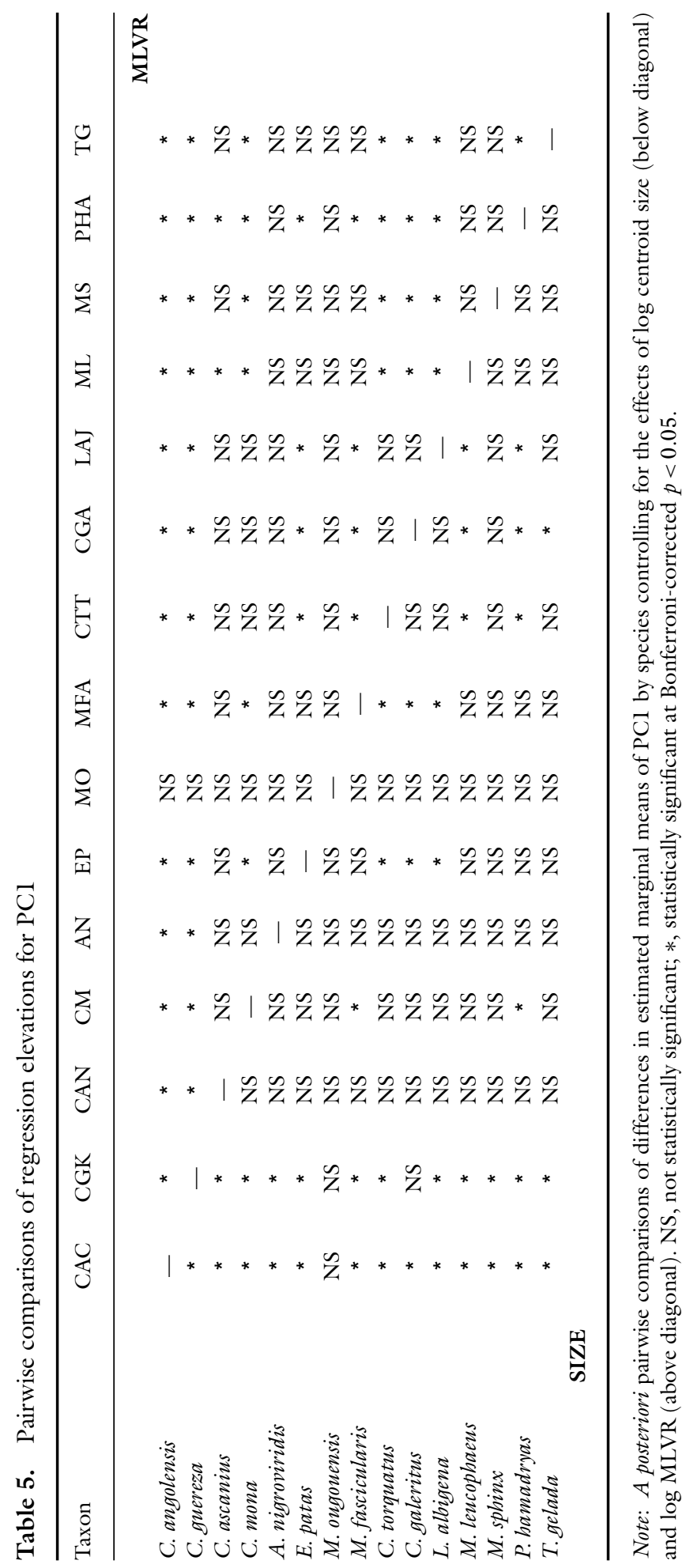


in comparison with similarly sized cercopithecines. Although few statistically significant differences are detected among cercopithecines, the patterning of allometric dissociations is clear. Like Colobus, the mangabeys exhibit negative displacements relative to other papionins and most cercopithecins (Table 4, Figure 4a), implying increased MA and bite force relative to cranial size. Scaling of PCl relative to MLVR has identical biomechanical implications: negative displacement of mangabey allometric lines results in shortened dental load arms relative to MLVR length. The mangabey MLVR regressions differ significantly from other papionins but overlap those of Cercopithecus and Miopithecus, which also exhibit negative displacement of elevations and a concomitant increase in MA relative to most cercopithecines. Owing to differences in scaling relative to centroid size, however, mangabeys maintain this advantage at relatively larger cranial sizes.

\section{Functional Allometry-Principal Component 2}

Scaling relationships for the 2 nd Principal Component ( $10 \%$ of total shape variance) are relatively complex. It is only weakly correlated with cranial centroid size across all individuals $(r=0.09, p=0.04)$ but moderately correlated within most cercopithecine species (Figure 4b, Table 2). At the tribal level, PC2 is strongly correlated with size in cercopithecins but uncorrelated in papionins (Table 3 ). The ANCOVA of PC2 by species with centroid size as covariate is significant $\left(F=51.6, p<0.001, r^{2}=0.78\right)$, but homogeneity of slopes is rejected $(p=0.002)$. Heterogeneity of slopes potentially invalidates pairwise comparisons; however, separate ANCOVA analyses conducted for cercopthecins and papionins, respectively, confirm homogeneity of slopes within each tribe and yield species ranks and pairwise comparison patterns almost identical to those observed for the full-sample analysis (Table 6). Estimated marginal means (Table 4) segregate African papionins (excluding Theropithecus) from all remaining species including Macaca. Among papionins, mangabey elevations are uniformly significantly different from the large-bodied taxa, with some discrepancy as to the position of Cercocebus torquatus. Only the position of Macaca is meaningfully affected by sample composition. The full-sample analysis finds it significantly different from all African papionins and indistinguishable from cercopithecins, but exploratory analyses (not shown) suggest a scaling pattern intermediate between the cercopithecin and African papionin clades. 


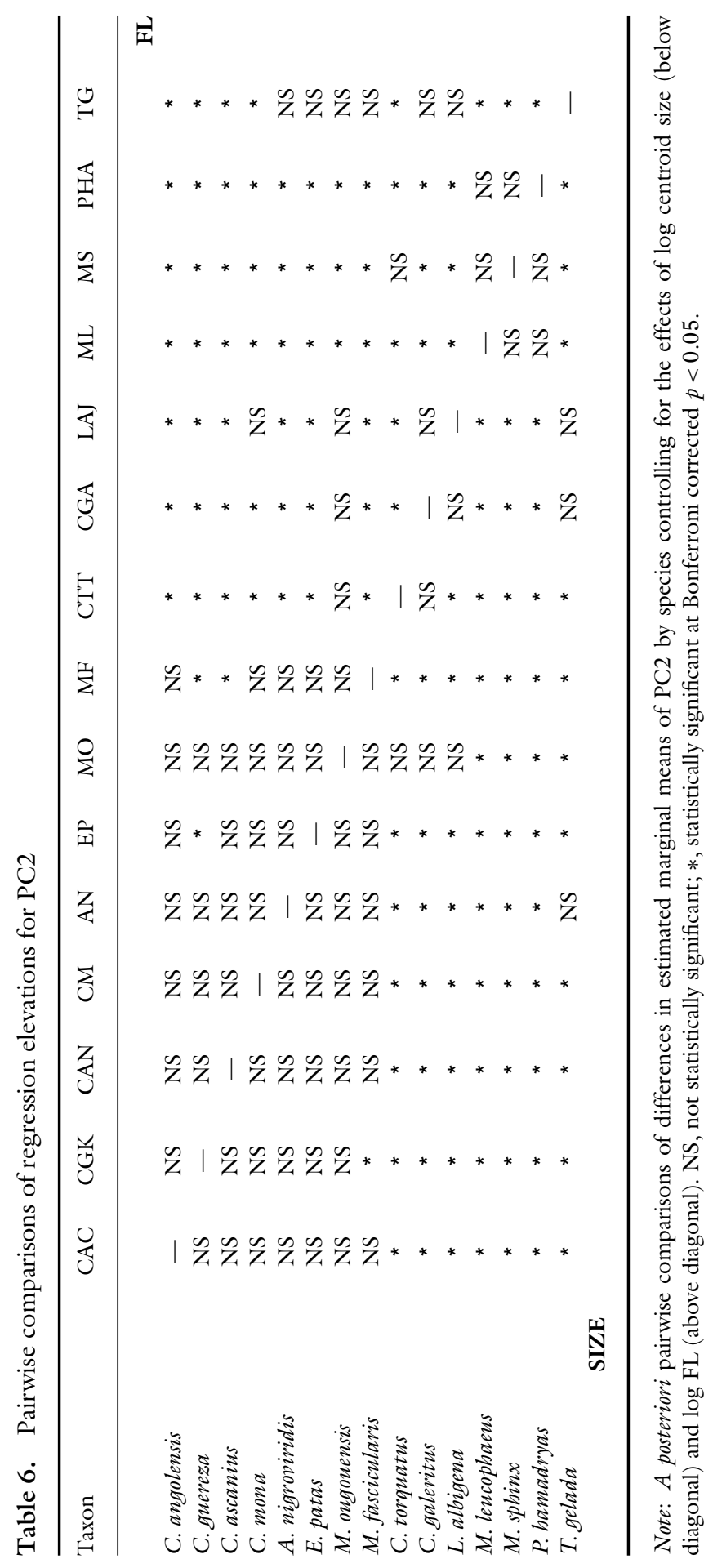



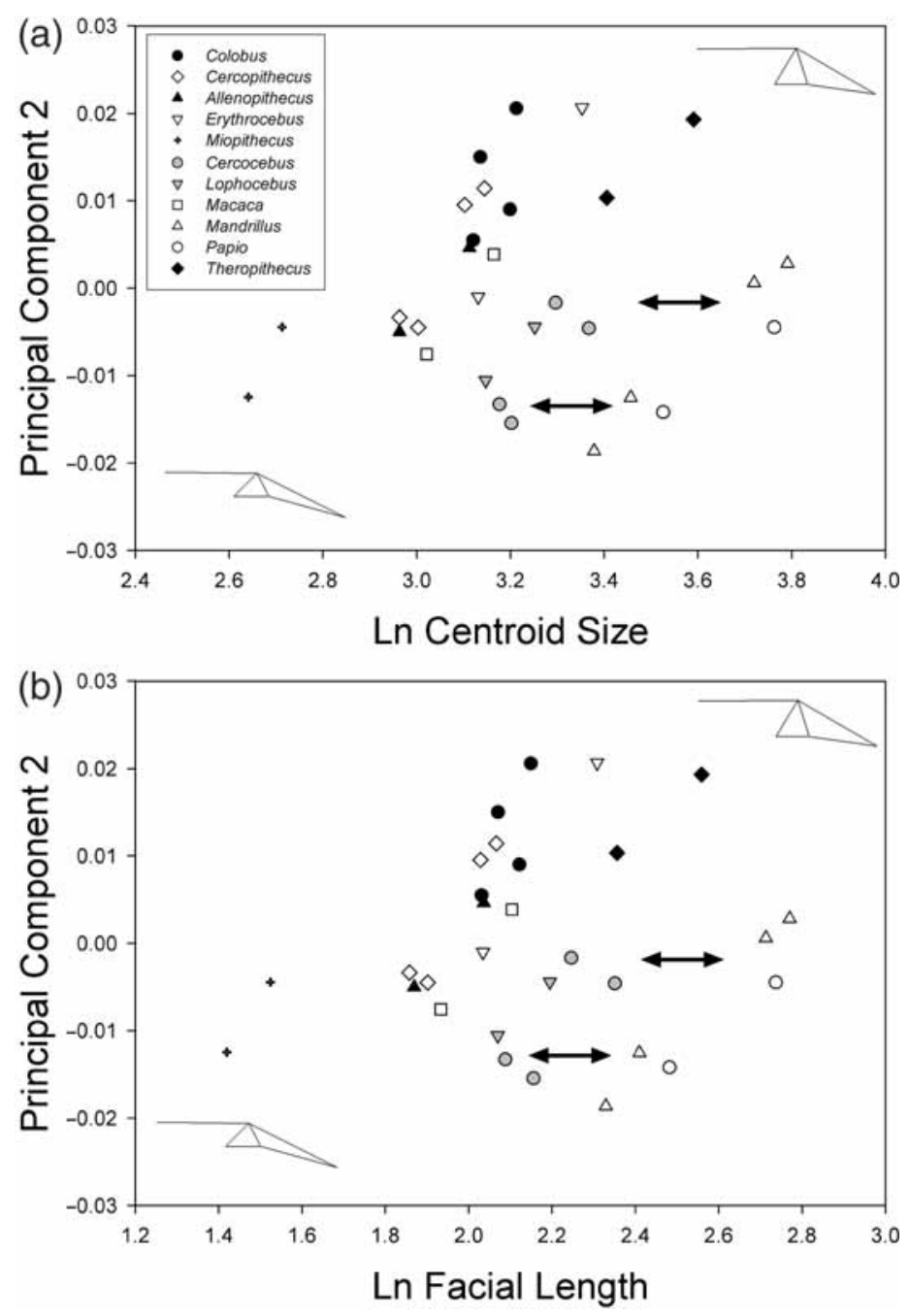

Figure 5. Plots of PC2 against log centroid size (a) and facial length (b) indicate geometric similarity (double-headed arrows) among African papioinins irrespective of size. Symbols represent male and female mean values for each species. Wireframes represent extremes of shape variation for PC2.

As with centroid size, FL shows strong linear correlations with PC2 within and across cercopithecin species (not shown), while papionins show moderate correlations within species and absence of correlation across species (Tables 2,3 ). The ANCOVA of PC2 by species with FL as covariate is significant $\left(F=53.2, p<0.001, r^{2}=0.79\right)$, homogeneity of slopes is confirmed, and pairwise comparisons (Table 6) are extremely similar to those for centroid size. 
Among African papionins, Papio and Mandrillus are significantly different from Lophocebus and C.galeritus but not C. torquatus, which also differs from other mangabeys. However, analysis restricted to papionins finds C. torquatus significantly different from all large-bodied African papionins and indistinguishable from other mangabey species.

The 2nd Principal Shape Component summarizes shape variation linked to relative gape. Intraspecific scaling of PC2 results in decreased relative gape and decreased vertical bite force components in males relative to conspecific females. A similar pattern is observed among cercopithecins, with larger taxa showing reduced gape relative to cranial size. Negative transposition of the African papionin regressions results in greater gape and potentially larger vertical bite forces than in comparably sized cercopithecins or Macaca. The autapomorphic facial morphology of Theropithecus hinders comparisons, but the negative displacement of its allometric line relative to cercopithecin species (Figure 4b) suggests that it shares this attribute. Dissociation of allometries among African papionins results in geometric similarity of relative TMJ position among species independent of size or FL (Figures 5a, b). Thus, Papio and Mandrillus maintain enhanced relative gape while dramatically increasing both FL and cranial size.

\section{DISCUSSION}

The present study is modeled upon Ravosa's (1990) comparison of masticatory scaling in colobines and cercopithecines and successfully replicates his major findings. Both analyses identify allometric dissociations between subfamilies resulting in enhanced relative MA in colobine species, and both show cercopithecines to be characterized by decreased relative MA and enhanced jaw gape. Whereas the prior study required 20 separate ANCOVA analyses (Ravosa, 1990), complicating interpretation of results and diminishing statistical power, analysis of Procrustes-based shape components required only four analyses, two of which ultimately proved redundant. In fact, scaling of principal shape components relative to centroid size and the biomechanical variables (MLVR and FL) yielded virtually identical taxonomic and functional interpretations. Thus, geometric analysis of functional shape variation does appear to provide a unified analysis of size and biomechanical allometries. Traditional linear regression analysis of metric variables will continue to be invaluable where parameter estimation and hypothesis testing relative to theoretical slopes 
are required. But where taxonomic differences in functional scaling and qualitative comparisons of functional shape trends are of primary interest, geometric methods offer significant advantages in terms of data reduction, analytic efficiency, internal consistency, and functional interpretation of results.

Ravosa (1990) hypothesized that differences in facial scaling between colobines and cercopithecines reflect functional tradeoffs between mechanical efficiency and gape. The present study identifies patterns of masticatory scaling indicative of similar, although less marked, functional divergences within and between cercopithecine tribes. Mangabey species exhibit facial allometries distinct from most other cercopithecines and similar in key respects to those of colobines. The facial shortening and retraction characteristic of these taxa increases the MA of the masseter muscle, resulting in greater relative bite force magnitudes, while simultaneously improving the dissipation of occlusal forces (Antón, 1996; Hylander, 1977, 1979; Ravosa, 1990). In colobines, which consume large volumes of fibrous matter requiring many chewing cycles, this configuration is seen as an adaptation for greater masticatory efficiency (Ravosa, 1990). In the case of Cercocebus and Lophocebus, both heavily reliant upon hard fruits, nuts, and seeds (Fleagle and McGraw, 1999; Kingdon, 1997; McGraw and Fleagle, 2000), maximization of bite force relative to cranial size is more likely to be the primary selective factor, and possibly key to successful exploitation of resistant foods by these small-bodied species. Although workers typically emphasize the link between facial shortening and molar biting (Antón, 1996; Du Brul, 1977; Hylander, 1979; Ravosa, 1990), recent studies have challenged the role of facial retraction in altering postcanine, but not incisal, bite forces (Greaves, 1995; Spencer, 1999). Perhaps not coincidentally, Cercocebus and Lophocebus are both characterized by enlarged incisors relative to molar size (Groves, 1978; Jablonski, 2002). Whether mangabey facial form is specifically adaptive for incisal preparation of hard fruits (Chalmers, 1968), postcanine crushing of nuts and seeds (Fleagle and McGraw, 2001), or both, is a question requiring further study.

Based upon outgroup comparisons with Macaca and cercopithecins (Figure 1), the shared masticatory form of mangabeys is most parsimoniously interpreted as homoplasious, the apparent result of functional convergence related to hard-object feeding. However, the intermediate position of the Macaca regression and apparent similarities in masticatory scaling between mangabeys, Miopithecus and C. mona combine to raise doubts concerning polarity of this trait. Because Miopithecus is a dwarf species characterized by 
decreased growth rates and greatly reduced terminal body size (Shea, 1992), it is likely that its facial geometry is the result of biomechanical scaling. To compensate for greatly reduced absolute masticatory muscle forces, changes in facial proportion similar to those observed for mangabeys are likely to have evolved to maintain minimum biomechanical competence (Shea, 1985, 1992; Smith, 1993). The case of C. mona, which differs from its congener in neither size nor dietary consistency, is less amenable to post hoc explanation (Kingdon, 1997). This discrepancy may reflect latent morphological diversity within the guenon clade or simple sampling effects, and its significance is unclear. Pending confirmatory studies incorporating additional guenon species, the hypothesis that shared mangabey facial forms are derived and homoplasious stands, albeit with a large asterisk.

Differences in the scaling of the 2nd Principal Component cause African papionins to exhibit increased mandibular gape relative both to cranial size and FL. The possession of enhanced relative gape distinguishes African papionins, including Theropithecus, from all cercopithecins as well as Macaca fascicularis. It is unknown whether African papionins are similarly distinguished from all Macaca species, but a finding of homogeneous facial scaling in M. fascicularis, M. mulatta, and M. sylvanus (Collard and O'Higgins, 2002) - the latter being the most basal and arguably the most primitive of the macaques (Morales and Melnick, 1998)—suggests this is likely. The intermediate position of Macaca between tribes contributes to an inconsistent pattern of pairwise comparisons and highlights the difficulty of drawing strong inferences of polarity for continuous traits, analyses of which are particularly susceptible to sample composition. Pending further investigation of this trait within genus Macaca, increased relative gape is most parsimoniously interpreted as a synapomorphy of the African papionin clade, that is, subtribe Papionina. Whereas cercopithecins exhibit decreased relative gape as cranial size increases, a dissociation of papionin elevations results in isometry among species and similar relative gape capacity irrespective of size or FL. Such displacements are commonly associated with selection for maintenance of functional equivalence as species enter new size ranges (Gould, 1971; Ravosa, 1992; Shea, 1983b, 1995; Smith, 1993; Vinyard and Ravosa, 1998), implying this aspect of papionin facial geometry has adaptive significance separate from cranial size (Gould, 1971; Shea, 1985). Assuming directional selection upon a continuous trait (relative gape), the intermediate position of mangabey regressions between the outgroups (Macaca and cercopithecins) and large-bodied papionins suggests that mangabeys most 
closely resemble the basal African papionin form. Thus, Papio and Mandrillus are inferred to have experienced homoplastic shifts in the scaling of gape leading to maintenance of enhanced gape at relatively large body sizes.

Gape is functionally correlated with both jaw length and canine size, and has been hypothesized to be the principal factor limiting canine height (Lucas, 1981, 1982; Ravosa, 1990). Gape is thus expected to be emphasized in largebodied species with pronounced sexual size and canine dimorphism (Greaves, 1974; Lucas, 1981, 1982; Lucas et al., 1986; Plavcan and van Schaik, 1993). Species which engage canines as weapons or in threat display-that is, terrestrial species subject to predation risk and social species with high levels of intraspecific competition-are also expected to exhibit increased gape (Lucas et al., 1986; Plavcan and van Schaik, 1993). These expectations are met in Papio, Mandrillus, and Theropithecus - large-bodied, terrestrial monkeys with extreme sexual size and canine dimorphism and intensive mate competition (Jolly, 1970) - but are less apt for the smaller bodied and more arboreal mangabeys. An alternative explanation for increased gape lies in its masticatory significance. Enhanced gape is thought to result in increased vertical bite forces, particularly in the incisal region (Ravosa, 1990), and has been hypothesized to confer selective advantages upon primates specializing in large-diameter foods or hard foods requiring incisal preparation (Hylander, 1979; Ravosa, 1990; Smith, 1984). Certainly, mangabeys fall into this category (see above), and largebodied African papionins are also known to consume a variety of resistant foods including hard fruits, nuts, seed pods, roots, and herbaceous matter (Kingdon, 1997). The last common ancestor of the African papionin radiation is believed to have resembled Parapapio, a moderately sized, terrestrial or semiterrestrial stem papioninan living in dry, mixed-cover, and open-country environments (Jablonski, 2002; Szalay and Delson, 1979). The ability to exploit resistant foods, especially nutrient-dense roots and seeds, would have been strongly selected under these conditions; thus, enhanced gape may have arisen initially as an adaptation to hard-consistency diets.

Under this scenario, subsequent allometric and functional shifts within the African papionin clade are hypothesized to reflect selection for maintenance or enhancement of specific functional capacities coincident with the origin of distinct papioninan ecomorphs. In the case of the small-bodied mangabeys, decreased absolute masticatory force is offset by altered masticatory scaling patterns that increase relative bite force and permit maintenance of the ancestral hard-object feeding regime at the smaller body sizes necessary for exploitation 
of arboreal niches. Conversely, increased body size in Papio and Mandrillus is associated with allometric displacements that effectively decouple gape from size. By increasing the efficiency of incisal biting (Ravosa, 1990), maintenance of enhanced gape may partially offset the loss of MA associated with increased FL; however, increased absolute masticatory forces associated with extreme body size reduce the practical impact of this effect (Ravosa, 1990). Similarly, at larger absolute cranial sizes, enhanced relative gape is no longer required to accommodate the largest food items typical to the primate diet. In the absence of clear masticatory benefits, dissociation of gape-size allometrieswhich in turn relaxes constraints on adult male canine size (Lucas, 1982; Lucas et al., 1986; Ravosa, 1990)—is best interpreted as a response to selection for increased canine size due to social or ecological factors (Harris, 2000, 2002; Jolly, 1970).

The preceding scenario draws upon phylogenetic, ontogenetic, biomechanical, and behavioral studies to infer the evolutionary history of papionin facial forms. The most plausible alternate scenario-that enhanced relative gape arose in the common African papionin ancestor in response to direct selection for increased canine height-is less consistent with current understanding of ancestral papioninan morphotype. Although estimated male body masses for the largest Parapapio species overlap those of extant Papio and Mandrillus (Delson et al., 2000), the smaller average body sizes, primitive cranial morphology, and moderate canine dimorphism of these basal papionins (Jablonski, 2002 ) tend to discount baboon-like canine enlargement as key to early papioninan adaptations. Still, the possibility that enhanced gape in combination with extreme canine dimorphism was the primitive African papionin condition cannot be dismissed. In this case, enhanced gape in mangabeys would be symplesiomorphic, maintained as a secondary adaptation to consumption of large-diameter foods or perhaps simply through phylogenetic inertia.

Of the inferences drawn here, the most controversial concern the polarity of mangabey masticatory allometries. The presence of shared patterns of masticatory scaling in these species mirrors previous findings that mangabeys share static and ontogenetic facial allometries distinct from those of largebodied papionins (Collard and O'Higgins, 2001; Leigh et al., 2003; Shah and Leigh, 1995; Singleton, 2002); however, most of these studies have interpreted mangabey facial allometries as symplesiomorphic. These two sets of results are not necessarily discordant. Patterns of localized functional scaling may have been "swamped" in previous analyses concerned with larger 
scale patterns of craniofacial allometry. Also, minor perturbations of shared ancestral ontogenetic allometries, arising in parallel under strong functional selection, could conceivably result in novel, homoplastic adult morphologies. Given the complexities of the systems in question, both developmental studies sampling the full range of cercopithecine taxonomic and morphological diversity and more nuanced functional analyses will be required to ultimately reconcile patterns of ontogenetic and functional allometry in this group.

\section{CONCLUSIONS AND SUMMARY}

This paper demonstrates but one possible application of geometric morphometrics to the functional interpretation of allometric shape variation-an area of historical bioanthropological interest. Geometric analysis is shown here to yield qualitatively similar results to distance-based linear regression analysis while offering advantages in terms of analytic efficiency and functional interpretation. Results reveal differences in functional scaling of the masticatory complex within and between cercopithecine tribes signaling functional and adaptive divergences. Relative to cercopithecins and Macaca, African papionins exhibit decreased relative height of the TMJ leading to enhanced mandibular gape and increased incisal bite forces. This shift is interpreted as a papioninan synapomorphy and is linked to selection for hard-object feeding capabilities in the last common ancestor of the African clade. Further dissociations within this group are tied to the subsequent ecomorphological divergence of small- and large-bodied African papionins. Allometric dissociations in Papio and Mandrillus that maintain enhanced gape at markedly increased body size are interpreted as homoplastic and related to accommodation of enlarged male canines. Similarly, homoplastic displacements of functional shape allometries in Cercocebus and Lophocebus enhance MA and increase relative bite forces, enabling continued exploitation of resistant food items at the smaller body sizes required for (semi)arboreality. An alternative scenario positing increased body size, canine enlargement, and enhanced gape as the basal papioninan condition cannot be excluded but is considered less likely based on reconstructions of the African ancestral morphotype. The scope of this study is, by necessity, limited, its results largely qualitative, and its conclusions tentative. Future studies sampling the true range of guenon and macaque craniofacial diversity are required to firmly establish morphocline polarities for the cercopithecine masticatory complex and construct 
robust functional and adaptive hypotheses. As demonstrated here, geometric morphometric analysis of functional allometry should contribute substantially to this effort.

\section{ACKNOWLEDGMENTS}

I thank Dennis Slice for inviting me to contribute to this volume, and I dedicate this work to the life and legacy of Les Marcus. His patient instruction and gentle (or not so) remonstrances are daily missed by those privileged to have worked and studied with him. I wish to thank Eric Delson for his continuing support of this research and David Reddy for his ongoing technical assistance. I am grateful to Steve Frost and Tony Tosi for their substantial contributions to the NYCEP Primate Morphometrics Database, to the numerous museum curators and collections managers who made amassing this resource possible, and to Richard Thorington and Linda Gordon (NMNH) for permission to photograph specimens in their care. I thank Dennis Slice, James Rohlf, Nicholas Jones, and Paul O'Higgins, among others, for continuing to upgrade and distribute the software upon which so many of us rely. Finally, I am grateful to Dennis Slice and an anonymous reviewer, whose comments considerably improved this contribution, as well the many colleagues who have shared advice and insights including Steve Frost, Kieran McNulty, Katerina Harvati, Sandra Inouye, Brian Shea, Edgar Allin, and Jim Cheverud. Any errors of fact, interpretation, or polarity determination are, needless to say, my own. This work was conducted with the support of the National Science Foundation via the New York Consortium in Evolutionary Primatology Morphometrics Group (NSF Research \& Training Grant BIR-9602234, NSF Special Program Grant ACI-9982351). This chapter is NYCEP Morphometrics Contribution No. 12.

\section{REFERENCES}

Antón, S. C., 1996, Cranial adaptation to a high attrition diet in Japanese macaques, Intl. J. Primatol. 17:401-427.

Barnicot, N. A. and Hewett-Emmett, D., 1972, Red cell and serum proteins of Cercocebus, Presbytis, Colobus and certain other species, Folia Primatol. 17: $442-457$.

Benefit, B. R. and McCrossin, M. L., 1991, Ancestral facial morphology of Old World higher primates, Proc. Nat. Acad. Sci. USA 88:5261-5271. 
Benefit, B. R. and McCrossin, M. L., 1993, Facial anatomy of Victoriapithecus and its relevance to the ancestral cranial morphology of Old World monkeys and apes, Am.J. Phys. Anthropol. 92:329-370.

Bookstein, F. L., 1985, Modeling differences in cranial form, with examples from primates, in: Size and Scaling in Primate Biology, W. L. Jungers, ed., Plenum Press, New York, pp. 207-229.

Bookstein, F. L., 1996, Combining the tools of geometric morphometrics, in: Advances in Morphometrics, L. F. Marcus, M. Corti, A. Loy, G. J. P. Naylor, and D. E. Slice, eds., Plenum Press, New York, pp. 131-151.

Bouvier, M., 1986a, A biomechanical analysis of mandibular scaling in Old World monkeys, Am. J. Phys. Anthropol. 69:473-482.

Bouvier, M., 1986b, Biomechanical scaling of mandibular dimensions in New World monkeys, Intl. J. Primatol. 7:551-567.

Cachel, S. M., 1984, Growth and allometry in primate masticatory muscles, Arch. Oral Biol. 29:287-293.

Chalmers, N. R., 1968, Group composition, ecology and daily activity of free living mangabeys in Uganda, Folia Primatol. 8:247-262.

Cheverud, J. M. and Richtsmeier, J. T., 1986, Finite-element scaling applied to sexual dimorphism in rhesus macaque (Macaca mulatta) facial growth, Syst. Zool. 35:381-399.

Cochard, L. R., 1985, Ontogenetic allometry of the skull and dentition of the rhesus monkey (Macaca mulatta), in: Size and Scaling in Primate Biology, W. L. Jungers, ed., Plenum Press, New York, pp. 231-255.

Collard, M. and O'Higgins, P., 2001, Ontogeny and homoplasy in the papionin monkey face, Evol. Devel. 3:322-331.

Collard, M. and O'Higgins, P., 2002, Why such long faces? A response to Eugene Harris, Evol. Devel. 4:169.

Collard, M. and Wood, B. A., 2000, How reliable are human phylogenetic hypotheses? Proc. Nat. Acad. Sci. USA 97:5003-5006.

Cronin, J. E. and Sarich, V. M., 1976, Molecular evidence for dual origin of mangabeys among Old World primates, Nature 260:700-702.

Delson, E., 1975a, Evolutionary history of the Cercopithecidae, in: Contributions to Primatology. Vol. 5: Approaches to Primate Paleobiology, F. S. Szalay, ed., Karger, Basel, pp. 167-217.

Delson, E., 1975b, Paleoecology and zoogeography of the Old World monkeys, in: Primate Functional Morphology and Evolution, R. Tuttle, ed., Mouton, The Hague, pp. 37-64.

Delson, E., Terranova, C. J., Jungers, W. L., Sargis, E. J., Jablonski, N. G., and Dechow, P. C., 2000, Body mass in Cercopithecidae (Primates, Mammalia): Estimation 
and scaling in extinct and extant taxa, Anthropol. Pap. Am. Mus. Nat. Hist. 83:1-159.

Demes, B., Creel, N., and Preuschoft, H., 1986, Functional significance of allometric trends in the hominoid masticatory apparatus, in: Primate Evolution, J. G. Else and P. C. Lee, eds., Cambridge University Press, Cambridge, pp. 229-237.

Disotell, T. R., 1994, Generic level relationships of the Papionini (Cercopithecoidea), Am. J. Phys. Anthropol. 94:47-57.

Disotell, T. R., 1996, The phylogeny of Old World monkeys, Evol. Anthropol. 5:18-24.

Disotell, T. R., Honeycutt, R. L., and Ruvolo, M., 1992, Mitochondrial DNA phylogeny of the Old World monkey tribe Papionini, Mol. Biol. Evol. 9:1-13.

Dryden, I. L. and Mardia, K. V., 1998, Statistical Shape Analysis, John Wiley, New York.

Du Brul, E. L., 1977, Early hominid feeding mechanisms, Am. J. Phys. Anthropol. 47:305-320.

Dutrillaux, B., Couturier, J., Muleris, M., Lombard, M., and Chauvier, G., 1982, Chromosomal phylogeny of forty-two species or subspecies of cercopithecoids (Primates, Catarrhini), Ann. Genet. 25:96-109.

Dutrillaux, B., Fosse, A. M., and Chauvier, G., 1979, Étude cytogénétique de six espèces ou sous-espèces de mangabeys (Papiinae [sic], Cercopithecoidea), Ann. Genet. 22:88-92.

Fleagle, J. G. and McGraw, W. S., 1999, Skeletal and dental morphology supports diphyletic origin of baboons and mandrills, Proc. Nat. Acad. Sci. USA 96:1157-1161.

Fleagle, J. G. and McGraw, W. S., 2001, Skeletal and dental morphology of African papionins: Unmasking a cryptic clade, J. Hum. Evol. 42:267-292.

Freedman, L., 1962, Growth of muzzle length relative to calvaria length, Growth 26:117-128.

Freedman, L., 1963, A biometric study of Papio cynocephalus skulls from northern Rhodesia and Nyasaland, J. Mammal. 44:24-43.

Frost, S. R., Marcus, L. F., Bookstein, F. L., Reddy, D. P., and Delson, E., 2003, Cranial allometry, phylogeography, and systematics of large-bodied papionins (Primates: Cercopithecinae) inferred from geometric morphometric analysis of landmark data, Anat. Rec. 275A:1048-1072.

Gould, S. J., 1966, Allometry and size in ontogeny and phylogeny, Biol. Rev. 41:587-640.

Gould, S. J., 1971, Geometric similarity in allometric growth: A contribution to the problem of scaling in the evolution of size, Am. Nat. 105:113-136.

Gould, S. J., 1975, Allometry in primates, with emphasis on scaling and the evolution of the brain, in: Contributions to Primatology. Vol. 5: Approaches to Primate Paleobiology. F. S. Szalay, ed., Karger, Basel, pp. 244-292. 
Greaves, W. S., 1974, The mammalian jaw mechanism-the high glenoid cavity, Am. Nat. 116:432-440.

Greaves, W. S., 1995, Functional predictions from theoretical models of the skull and jaws in reptiles and mammals, in: Functional Morphology in Vertebrate Paleontology, J. J. Thomason, ed., Cambridge University Press, Cambridge, pp. 99-115.

Groves, C. P., 1978, Phylogenetic and population systematics of the mangabeys (Primates: Cercopithecoidea), Primates 19:1-34.

Harris, E. E., 2000, Molecular systematics of the Old World monkey tribe Papionini: Analysis of the total available genetic sequences, J. Hum. Evol. 38:235-256.

Harris, E. E., 2002, Why such long faces? Response to Collard and O'Higgins, Evol. Devel. 4:167-168.

Harris, E. E. and Disotell, T. R., 1998, Nuclear gene trees and the phylogenetic relationships of the mangabeys (Primates: Papionini), Mol. Biol. Evol. 15:892-900.

Herring, S. W. and Herring, S. E., 1974, The superficial masseter and gape in mammals, Am. Nat. 108:561-576.

Hewett-Emmett, D., Cook, C. N., and Barnicot, N. A., 1976, Old World monkey hemoglobins: Deciphering phylogeny from complex patterns of molecular evolution, in: Molecular Evolution, M. Goodman and R. E. Tashian, eds., Plenum Press, New York, pp. 257-275.

Hill, W. C. O., 1974, Primates: Comparative Anatomy and Taxonomy. Vol. 7: Catarrhini, Cercopithecinae, Cercocebus, Macaca, and Cynopithecus, Edinburgh University Press, Edinburgh.

Huxley, J. S., 1932, Problems of Relative Growth, Methuen, London.

Hylander, W. L., 1977, The adaptive significance of Eskimo craniofacial morphology, in: Orofacial Growth and Development, A. A. Dahlberg and T. M. Graber, eds., Mouton, Paris, pp. 129-170.

Hylander, W. L., 1979, The functional significance of primate mandibular form, J. Morph. 106:223-240.

Hylander, W. L., 1985, Mandibular function and biomechanical stress and scaling, Am. Zool. 25:315-330.

Jablonski, N. G., 2002, Fossil Old World monkeys: The late Neogene radiation, in: The Primate Fossil Record, W. C. Hartwig, ed., Cambridge University Press, Cambridge, pp. 255-299.

Jolicoeur, P., 1963, The multivariate generalization of the allometry equation, Biometrics 19:497-499.

Jolly, C. J., 1970, The large African monkeys as an adaptive array, in: Old World Monkeys: Evolution, Systematics, and Behavior, J. R. Napier and P. H. Napier, eds., Academic Press, New York, pp. 141-174.

Kingdon, J., 1997, The Kingdon Field Guide to African Mammals, Academic Press, San Diego. 
Kuhn, H.-J., 1967, Zur systematik der Cercopithecidae, in: Nene Ergebnisse der Primatologie, D. Starck, R. Schneider, and H.-J. Kuhn, eds., G. Fischer, Stuttgart, pp. 25-46.

Leigh, S. R., Shah, N. F., and Buchanan, L. S., 2003, Ontogeny and phylogeny in papionin primates, J. Hum. Evol. 45:285-316.

Lockwood, C. A. and Fleagle, J. G., 1999, The recognition and evaluation of homoplasy in primate and human evolution, Yearb. Phys. Anthropol. 42:189-232.

Lucas, P. W., 1981, An analysis of canine size and jaw shape in some Old and New World non-human primates, J. Zool. 195:437-448.

Lucas, P. W., 1982, An analysis of the canine tooth size of Old World higher primates in relation to mandibular length and body weight, Arch. Oral Biol. 27:493-496.

Lucas, P. W., Corlett, R. T., and Luke, D. A., 1986, Sexual dimorphism of tooth size in anthropoids, Hum. Evol. 1:23-39.

McGraw, W. S., and Fleagle, J. G., 2000, Biogeography and evolution of the CercocebusMandrillus clade, Am. J. Phys. Anthropol. Suppl. 30:225.

McNamara, J. A., Riolo, M. L., and Enlow, D. H., 1976, Growth of the maxillary complex in the rhesus monkey (Macaca mulatta), Am. J. Phys. Anthropol. 44:15-26.

Morales, J. C. and Melnick, D. J., 1998, Phylogenetic relationships of the macaques (Cercopithecidae: Macaca), as revealed by high resolution restriction site mapping of mitochondrial ribosomal genes, J. Hum. Evol. 34:1-23.

Mosimann, J. E. and Malley, J. D., 1979, Size and shape variables, in: Multivariate Methods in Ecological Work, L. Orioci, C. R. Rao and W. M. Stiteler, eds., International Co-Operative Publishing House, Fairland, MD, pp. 175-189.

O'Higgins, P. and Jones, N., 1998, Facial growth in Cercocebus torquatus: An application of three-dimensional geometric morphometric techniques to the study of morphological variation, J. Anat. 193:251-272.

O'Higgins, P. and Jones, N., 1999, Morphologika, University College London, London.

Page, S. L., Chiu, C., and Goodman, M., 1999, Molecular phylogeny of Old World monkeys (Cercopithecidae) as inferred from $\gamma$-globin DNA sequences, Mol. Phyl. Evol. 13:348-359.

Penin, X., Berge, C., and Baylac, M., 2002, Ontogenetic study of the skull in modern humans and the common chimpanzee: Neotenic hypothesis reconsidered with a tridimensional Procrustes analysis, Am. J. Anat. 118:50-62.

Plavcan, J. M. and van Schaik, C. P., 1993, Canine dimorphism, Evol. Anthropol. 2:208-214.

Profant, L. P. and Shea, B. T., 1994, Allometric basis of morphological diversity in the Cercopithecini vs Papionini tribes of Cercopithecine monkeys, Am. J. Phys. Anthropol. Suppl. 18:162-163. 
Ravosa, M. J., 1990, Functional assessment of subfamily variation in maxillomandibular morphology among Old World monkeys, Am. J. Phys. Anthropol. 82:199-212.

Ravosa, M. J., 1992, Allometry and heterochrony in extant and extinct Malagasy primates, J. Hum. Evol. 23:197-217.

Ravosa, M. J., and Profant, L. P., 2000, Evolutionary morphology of the skull in Old World monkeys, in: Old World Monkeys, P. F. Whitehead and C. J. Jolly, eds., Cambridge University Press, Cambridge, pp. 237-268.

Ravosa, M. J., and Shea, B. T., 1994, Pattern in craniofacial biology: Evidence from the Old World monkeys (Cercopithecidae), Intl. J. Primatol. 15:801-822.

Richtsmeier, J. T. and Lele, S., 1993, A coordinate-free approach to the analysis of growth patterns: Models and theoretical considerations, Biol. Rev. 68:381-411.

Rohlf, F. J., 1998, tpsSmall. Department of Ecology and Evolution, State University of New York-Stony Brook, Stony Brook, New York.

Rohlf, F. J., 1999, Shape statistics: Procrustes superimpositions and tangent spaces, J. Class. 16:197-223.

Rohlf, F. J. and Marcus, L. F., 1993, A revolution in morphometrics, Trends Ecol. Evol. 8:129-132.

Sakka, M., 1985, Cranial morphology and masticatory adaptations, in: Food Acquisition and Processing in Primates, D. J. Chivers, B. A. Wood, and A. Bilsborough, eds., Plenum Press, New York, pp. 415-427.

Shah, N. F. and Leigh, S. R., 1995, Cranial ontogeny in three papionin genera, Am.J. Phys. Anthropol. Suppl. 20:194.

Shea, B. T., 1983a, Allometry and heterochrony in the African apes, Am. J. Phys. Anthropol. 62:275-289.

Shea, B. T., 1983b, Size and diet in the evolution of African ape craniodental form, Folia Primatol. 40:32-68.

Shea, B. T., 1985, Ontogenetic allometry and scaling: A discussion based on the growth and form of the skull in African apes, in: Size and Scaling in Primate Biology, W. L. Jungers, ed., Plenum Press, New York, pp. 175-205.

Shea, B. T., 1992, Ontogenetic scaling and skeletal proportions in the talapoin monkey, J. Hum. Evol. 23:283-307.

Shea, B. T., 1995, Dissociability of size and shape in studies of allometry and morphometrics, Am. J. Phys. Anthropol. Suppl. 20:194.

Singleton, M., 2002, Patterns of cranial shape variation in the Papionini (Primates: Cercopithecinae), J. Hum. Evol. 42:547-578.

Slice, D. E., 2001, Landmark coordinates aligned by Procrustes analysis do not lie in Kendall's shape space, Syst. Biol. 50:141-149.

Slice, D. E., Bookstein, F. L., Marcus, L. F., and Rohlf, F. J., 1996, Appendix IA glossary for geometric morphometrics, in: Advances in Morphometrics, 
L. F. Marcus, M. Corti, A. Loy, G. J. P. Naylor, and D. E. Slice, eds., Plenum Press, New York, pp. 531-551.

Smith, R. J., 1984, Comparative functional morphology of maximum mandibular opening (gape) in primates, in: Food Acquisition and Processing in Primates, D. J. Chivers, B. A. Wood, and A. Bilsborough, eds., Plenum, New York, pp. 231-255.

Smith, R. J., 1993, Categories of allometry: Body size versus biomechanics, J. Hum. Evol. 24:173-182.

Spencer, M. A., 1999, Constraints on masticatory system evolution in anthropoid primates, Am. J. Phys. Anthropol. 108:483-506.

Strasser, E. and Delson, E., 1987, Cladistic analysis of cercopithecid relationships, J. Hum. Evol. 1 6:81-99.

Swindler, D. S. and Sirianni, J. E., 1973, Palatal growth rates in Macaca nemestrina and Papio cynocephalus, Am. J. Phys. Anthropol. 38:83-92.

Swindler, D. S., Sirianni, J. E., and Tarrant, L. H., 1973, A longitudinal study of cephalofacial growth in Papio cynocephalus and Macaca nemestrina from three months to three years, in: Symposium of the IVth International Congress of Primatology. Vol. 3 : Craniofacial Biology of the Primates, M. Zingeser, ed., Karger, Basel, pp. 227-240.

Szalay, F. S. and Delson, E., 1979, Evolutionary History of the Primates, Academic Press, New York.

Thorington, R. W. and Groves, C. P., 1970, An annotated classification of the Cercopithecoidea, in: Old World Monkeys-Evolution, Systematics, and Behavior, J. R. Napier and P. H. Napier, eds., Academic Press, New York, pp. 629-648.

Van Der Kuyl, A. C., Kuiken, C. L., Dekker, J. T., Perizonius, W. R. K., and Goudsmit, J., 1995, Phylogeny of African monkeys based upon mitochondrial 12S rRNA sequences, J. Mol. Evol. 40:173-180.

Vidarsdottir, U. S., O’Higgins, P., and Stringer, C., 2002, A geometric morphometric study of regional differences in the ontogeny of the modern human facial skeleton, J. Anat. 201:211-229.

Vinyard, C. J. and Ravosa, M. J., 1998, Ontogeny, function, and scaling of the mandibular symphysis in papionin primates, J. Morph. 235:157-175. 